\title{
Influence Factors of Foreign Direct Investment: Literature Review
}

\author{
Yinglong Yang ${ }^{1, *}$, Xianmei Fan², Yiping Wang ${ }^{3}$ \\ ${ }^{1}$ Business School, Hunan Normal University, Changsha, 410081, China \\ ${ }^{2}$ College of Commerce, Chengdu University of Technology, Chengdu, 610059, China \\ ${ }^{3}$ School of Economics, Lanzhou University, Lanzhou, 730100, China \\ *Corresponding Author: Yinglong Yang
}

Keywords: Foreign direct investment, Influence factors, Literature review

\begin{abstract}
Since 2000, the "going out" strategy has been promoted to a new height of a major strategy that concerns the overall situation and China's future development. China's foreign direct investment grown rapidly in total in the last 18 years and has become the second largest foreign investment country in the world. On one hand, this paper discusses the influence factors of foreign direct investment in general. On the other hand, this paper also combs the literature reviews of China's foreign direct investment factors from the perspectives of a single factor of economic factor, culture factor, institutional factor or cost factor. On this basis, this paper gives some suggestions to further expand the scale of foreign direct investment, and provides some references for relevant researchers.
\end{abstract}

\section{Introduction}

Since the reform and opening up, China's economic scale has been expanding. The government timely put forward the strategy of going out to encourage enterprises to make cross-border investment. Especially after China's accession to the WTO, enterprises' foreign direct investment has shown an obvious upward trend, the investment field has been expanding, and the location choice has become more extensive. In 2015, China's foreign direct investment flew for the first time exceeded the level of attracting foreign investment in the same period, ranking second in the world for the first time. China's foreign direct investment has achieved thirteen consecutive years of growth since 2003. Foreign investment of Chinese enterprises has entered a new stage. Total investment has increased rapidly. From the total investment volume, China's total foreign direct investment growth is very fast. The main body of investment is state-owned enterprises. From the perspective of investors, although the investment share of state-owned enterprises has declined, it is still the absolute main force of China's foreign direct investment. China's foreign direct investment not only tends to diversify, but also rationalize the industry structure of a good situation has begun to emerge. The regional distribution of China's foreign direct investment shows agglomeration effect, most of which are concentrated in Asia, followed by Latin America and Africa. This paper combs the relevant literature at home and abroad in order to further enrich and improve the existing theoretical system, and provide some help for China's enterprises OFDI (Outward Foreign Direct Investments) location selection.

\section{Discussion of Influence Factors of Foreign Direct Investment in General}

The cost school represented by Duneng holds that cost factors have an important impact on the location choice of OFDI. Since the expansion of product sales is the main driving force for FDI, tariffs, host country institutional environment (including economic and political systems) and operating environment will affect the location choice of enterprises. Buckley and Cousin argue that the main purpose of OFDI is to lock in risks and reduce transaction costs by internalizing external transaction costs. At the same time, the home country enterprises will preferentially choose the host country (or region) with lower transaction costs for investment, and the cultural and institutional 
differences will increase the transaction costs of enterprises, thus affecting the OFDI location choice. Kogut and Chang first studied OFDI's technology seeking motivation. By investigating the direct investment of Japanese manufacturing enterprises in the United States, they find that the main purpose of Japanese OFDI is to obtain new technology and knowledge information from the host country to improve the value-added technology of enterprise products and thereby enhance the core competitiveness of enterprises. Therefore, whether the host country has abundant technical resources and human capital is an important factor affecting the location choice of OFDI for multinational enterprises.

Some scholars put the location factors of the host country, the investment enterprises themselves, the driving factors of the home country and the investment motivation of the enterprises into a comprehensive consideration. They think that the OFDI location selection decision-making of Chinese enterprises should take these factors into account in a comprehensive and dynamic perspective. Location factors include environmental, economic and institutional factors (investment climate, growth rate of market economy, quality and cost of labor, etc.). The factors of investment enterprises include the competitive advantage, the scale and the stage of transnational operation, the industries or quasi-fields of investment. While considering the above factors, attention should also be paid to the space distance between the investor country and the host country, language and culture, national habits, political relations and historical links between countries. In addition, some scholars adopt different research methods, taking several OFDI countries or regions as samples, intercepting data from different periods to analyze the impact of some different factors on OFDI of Chinese enterprises. They believe that the host country's agglomeration economy, the host country's per capita national income level of the host country's market size, bilateral trade relations or bilateral exchange rate changes, cultural distance and geographical distance from the host country's natural resources endowment and the level of opening up, the host country's infrastructure conditions, the host country's political system environment and the appreciation of the RMB and other factors. It will affect the location choice of OFDI in Chinese enterprises.

\section{Discussion of Influence Factors of Foreign Direct Investment from the Perspective of a Single Factor}

\subsection{Economic Factor}

Kolstad and Wiig use China's investment data from 2003 to 2006 in 142 countries to conclude that host countries with abundant natural resources and low institutional level in the market scale are attractive to China's ODI. The former mainly exists in OECD countries, while the latter exists in non-OECD countries. However, Kang and Jiang's research has drawn different conclusions. It is found that the market size of the host country does not affect the investment choice of Chinese enterprises. Higher degree of economic freedom has a positive impact on attracting investment of Chinese enterprises. Wang Yongqin and others used the sample of Chinese enterprises' foreign to discuss the influence of tax factors on the location choice. The results show that Chinese enterprises have obvious motivation of tax avoidance and resource acquisition, and there is a substitution relationship between the quality of the host country's system and the tax avoidance function. Tian Wei and Yu Miaojie set up a general model of the influence of exchange rate factors on China's heterogeneous export enterprises. They believe that the influence of exchange rate on trade service-oriented investment and productive investment is different. The rise of exchange rate in the home country will promote the export of enterprises and make enterprises tend to choose trade service-oriented investment rather than productive investment. They also use 20002. This hypothesis was verified by a sample of micro-enterprises in 2008. It was found that $10 \%$ of the rise in China's exchange rate increased the probability of enterprises choosing trade-service investment. Huang Xian and Zhang Yu based on Yeaple's heterogeneous enterprise investment location choice model, added the host country consumer heterogeneity preference hypothesis, established the multinational enterprise foreign investment decision-making model to analyze the influencing factors and the 
mechanism of its effect, and adopted the 2003-2015 China to 98 countries (regions) investment data and time-varying coefficient model test, the results were issued. The demand structure of the current host country has a significant negative impact on enterprises 'overseas investment at the level of $5 \%$.

\subsection{Culture Factor}

Some scholars will classify culture as an informal institutional factor. For example, Qi Chunling and others believe that the higher the quality of the formal system of the host country has a significant positive impact on China's foreign investment, and the better the quality of the formal system of the host country is, the more it will attract China's investment. In the informal system, the host country's Chinese-American relationship assets have a significant positive impact on China's investment, while the informal institutional distance (cultural distance) will hinder China's foreign investment. Zheng Ying and others believe that cultural distance and formal institutional risk have a negative impact on the location choice of OFDI in China's enterprises, and the negative impact of formal institutional risk is weakened when the enterprises have a high level of OFDI experience or more international equity alliances. The negative impact of cultural distance is only reduced when the enterprise has a higher level of OFDI experience. Specific organizational learning can help Chinese enterprises overcome the obstacles in OFDI process caused by the formal and informal institutional environment of the host country. The investment of Chinese enterprises in other countries will also be influenced by the cultural distance between the home country and the host country, which comes from such factors as language and religious beliefs, cultural circles, the number of overseas Chinese and diplomatic relations between the two countries. It is generally believed that a large cultural distance between the two countries will increase the management cost and investment risk of transnational operations and have a negative impact on attracting investment. Bastos and Silva argue that the cost of understanding market demand and establishing production networks will be reduced by the home country migration network developed in the host country and the use of cross-border Portuguese enterprises. The operational data confirm the hypothesis.

\subsection{Institutional Factor}

Zhao Chunming and others believe that a free and open economic system and a welcoming attitude towards foreign investment are the most important of all institutional factors. Deng Ming pointed out that the economic system has a significant positive impact on the absorption of developing countries, while the impact on developed countries is not significant Yan Daying believes that the quality of the host country's economic system plays the most obvious role in the decision-making of FDI location. Chi Jianyu and others believe that China is more inclined to invest directly in the market economy rather than in the developed countries. Chi Jianyu and others believe that the quality of the host country's political and legal system has a significant positive impact on OFDI of Chinese enterprises, and the investment behavior is market-oriented, trying to avoid political risks. Liu Le and others believe that the host country's socio-economic conditions, investment returns, religious conflicts and other political risks have a significant positive impact on OFDI in China's enterprises. He Shufeng and others believe that political beliefs, political friction, international status, political relationship positioning and other political factors significantly affect the location choice of OFDI enterprises in China. Chen Song and others believe that the host country with low governance level is more attractive to our OFDI location choice, and the stability of the host country regime, the level of rule of law and the impact on corruption control are weaker than the host country government effectiveness, regulatory quality. Wang Yongqin and others pointed out that China's OFDI is less concerned about the political system and stability of the host country, but more concerned about government efficiency, supervision quality and corruption control, and tends to avoid countries with strict legal system. Meng Xing and others believe that with the increase of overseas investment experience, the host country's political risk has a more and more significant impact on location choice. The degree of concern of the enterprise depends on the bilateral relationship between our country and the host country. 


\subsection{Cost Factor}

With the continuous improvement of China's economic development level, China's labor costs and land resources have emerged supply bottlenecks, so that China's labor-intensive enterprises as the representative of investors began to consider investing in some countries with relatively low labor prices and relatively rich land resources. For example, in recent years, Chinese enterprises have begun to invest in building factories in ASEAN countries such as Myanmar, Cambodia and some African countries. The study of Li Yang, Zang Xin and Xue Mantian (2013) pointed out that the per capita national income of the host country was the proxy variable of labor cost. Because the higher the per capita national income of the host country, the greater the labor cost of the host country, the less direct investment the host country attracts for the purpose of pursuing low-cost labor. In addition to bypassing the trade barriers of the host country and maintaining and opening up the product market, FDI also carries the function of compensating for the shortage of domestic technology resources by developing high-tech and R\&D cooperation: with the rapid development of China's economy, more and more enterprises realize that technology is to achieve product differentiation. And maintain the core competitiveness of enterprises and promote the upgrading of product structure. In the pursuit of profit maximization, production cost plays an important role in the location of FDI. Labor cost is the key factor in manufacturing, especially in labor-intensive industries. According to Dunning's theory of national production compromise, manufacturers will use the minimum cost to maximize profits, in which labor cost is undoubtedly an important location factor. Multinational enterprises always start the internationalization process from the countries with close geographical or psychological distance, so the geographical distance factor is also an important factor affecting the location choice. Generally speaking, the greater the geographical distance, the smaller the liquidity of outward FDI. Conversely, the smaller the geographical distance, the greater the liquidity of outward FDI. In today's world economy and investment development process, transportation, information and communication, hydropower supply and other infrastructure plays an increasingly important role.

\section{Some Suggestions of Further Increasement of Foreign Direct Investment}

The scale of China's foreign direct investment has increased rapidly in recent years, but the overall scale is still very small compared with the absorption of investment. The main factors affecting the scale of outward FDI are savings and foreign exchange reserves. Therefore, it is necessary for us to further reduce the surplus of capital and financial items in the balance of payments by expanding the scale of foreign direct investment. Theoretically speaking, increasing the amount of savings and reducing foreign exchange reserves are two feasible methods, but the effectiveness of these two methods in reality is still worth further deliberation. China's savings will not increase greatly in the future, and will play a limited role in promoting the expansion of foreign direct investment. Our country must use foreign exchange reserves to expand foreign direct investment. At present, China's current account and capital account double surplus, and because the vast majority of the capital account has not yet opened, so the huge foreign exchange reserves are mainly formed through trade balance and direct investment. Excessive foreign exchange reserves put it under pressure of appreciation and may face the risk of international exchange rate fluctuation. Therefore, it is necessary for China to reduce the scale of foreign exchange reserves appropriately. Considering the important role of foreign trade in China's economic growth and employment expansion, we cannot reduce foreign exchange reserves by restricting exports or expanding imports. Therefore, increasing foreign direct investment has become an effective way to reduce foreign exchange reserves. As a supervisor and guide, the government should provide a good environment for private enterprises to carry out foreign direct investment.

\section{Acknowledgement}

This research is the result of Hunan Province College Students Research Learning and Innovative 
Experiment Project (201810542009).

\section{References}

[1] Ji Kaiwen, Zhou Ji. The Efficiency and Influencing Factors of Chinese Outward Foreign Direct Investment Along "the Belt and Road" Based on SFA Gravity Model [J]. Review of Economy and Management, 2018(4): 138-148.

[2] Cai Zhibing, Zu Qiang. The Influencing Factors of The Growth of China's Foreign Direct Investment -Based on Factor Analysis Model [J]. International Business, 2012(3): 80-88.

[3] Wang Sheng, Tian Tao. The Determinants of the Location Choice of OFDI from China: A Research Based on the Perspective of Country Specific Difference [J]. World Economy Studies, 2013(12): 60-66+86.

[4] Jiang Nengpeng, He Pei, Chen Jinzhi. China's Outward Foreign Direct Investment and Technology Innovation: Based on the Perspective of Factor Market Distortion [J]. Journal of Zhejiang University (Humanities and Social Sciences), 2018(8): 99-112. 